\title{
REVERSE PHASE HIGH PERFORMANCE LIQUID CHROMATOGRAPHIC METHOD DEVELOPMENT BASED ON ULTRAVIOLET- VISIBLE DETECTOR FOR THE ANALYSIS OF 1-HYDROXYPYRENE (PAH BIOMARKER) IN HUMAN URINE
}

\author{
ATIF KAMAL ${ }^{1}$, MOHAMMAD GULFRAZ ${ }^{2}$, MOHAMMAD ASAD ANWAR ${ }^{2}$, \\ and RIFFAT NASEEM MALIK ${ }^{1}$
}

${ }^{1}$ Quaid-i-Azam University, Islamabad, Pakistan

Faculty of Biological Sciences, Department of Environmental Sciences, Environmental Biology

and Ecotoxicology Laboratory

${ }^{2}$ Pir Mehr Ali Shah, Arid Agriculture University, Rawalpindi, Pakistan

Institute of Biochemistry

\begin{abstract}
Objectives: 1-hydroxypyrene is an important biomarker of exposure to polycyclic aromatic hydrocarbons (PAHs), which appears in the urine of exposed human subjects. In developing countries, where advanced instruments are not available, the importance of this biomarker demands convenient and sensitive methods for determination purposes. This study aimed at developing a methodology to quantify 1-hydroxypyrene (a biomarker of PAHs exposure) based on the UV-visible detector in the reverse phase high pressure liquid chromatography (HPLC). Material and Methods: A $20 \mu l$ injection of sample was used for manual injection into the HPLC Shimadzu, equipped with the SPD-20 A UV-visible detector, the LC-20AT pump and the DGU-20A5 degasser. The C-18 column was used for the purpose of the analysis. Results: The method showed a good linearity (the range: $\mathrm{R}^{2}=0.979-0.989$ ), and high detectability up to the nmol level. The average retention was 6.37 , with the accuracy of $2 \%$, and the percentage of recovery remained $108 \%$. The overall performance of this method was comparable (in terms of detection sensitivity) and relatively better than previously reported studies using the HPLC system equipped with the UV-detector. Conclusions: This method is suitable and reliable for the detection/quantification of the 1-OHP in human urine samples, using the UV-detector, however, it is less sensitive as compared to the results of a florescence detector.
\end{abstract}

Key words:

1-OHP, 1-Hydroxypyrene, High pressure liquid chromatography, Pakistan, Biomarkers of exposure, PAHs

Received: May 13, 2014. Accepted: September 19, 2014.

Corresponding author: R.N. Malik, Quaid-i-Azam University, Environmental Biology and Ecotoxicology Laboratory, Islamabad, Pakistan (e-mail: r_n_malik2000@yahoo.co.uk). 


\section{INTRODUCTION}

Exposure to environmental contaminants is often evaluated using tools known as biomarkers of exposure [1,2]. The urinary 1-hydroxypyrene (1-OHPyr) is a reliable and sensitive biomarker of exposure to the low-level occupational and environmental exposure to polycyclic aromatic hydrocarbons (PAHs). 1-OHPyr is one of the metabolites of PAHs, and can be used as a good biological indicator of exposure to the mixture of PAHs [3-5].

The urinary levels of the 1-OHPyr are commonly determined using the high pressure liquid chromatography (HPLC) equipped with a fluorescence detector, however, a limited number of literature studies has also referred to the UV-visible detector with the HPLC used for this purpose, whereas the quantified 1-OHPyr is also being carried out using a gas chromatography/mass spectrometry (GC/MS), which is the most preferable due to its high sensitivity and reliability, however, the procedures for sample cleanup for the GC/MS analysis are very laborious, limiting its usage [5]. Nevertheless, in many developing countries, such high sensitive techniques are rarely available; HPLC systems are commonly equipped with the UV-visible detector. Since we could not access any reliable method based on the UV-visible analysis for quantification of the 1-OHPyr, this study therefore aimed at developing a methodology in order to evaluate the efficiency of the UV-visible detector to quantify the 1-OHPyr in human urine, and providing a convenient method for quantification of the urinary 1-OHPyr.

\section{MATERIAL AND METHODS}

Chemicals used for the method development included the HPLC gradient grade water, from Sigma-Aldrich ( $99.8 \%$ pure), acetonitrile (98.9\% pure), the 1-hydroxypyrene biomarker (1-OHPyr, linear formula $(\mathrm{LF})=\mathrm{C}_{16} \mathrm{H}_{10} \mathrm{O}$, molecular weight $(\mathrm{MW})=218.25$, $98 \%$ pure), that was purchased from sigma-Aldrich. All the glassware (Pyrex) was thoroughly washed with $5 \% \mathrm{HNO}_{3}$, including subsequent washing with distilled water, and oven drying. The standards were prepared in the HPLC-grade acetonitrile ( $\mathrm{mmol} / \mathrm{l})$. Serial dilutions of standards were carried out using the stock of $1 \mathrm{mmol} / \mathrm{l}$ in strength. The stock standard was diluted up to $\mathrm{nmol} / \mathrm{l}$. All the dilutions were prepared afresh each day before starting the calibration procedure. The stock standards were kept in a refrigerator in sterile glass vials to avoid solvent evaporation and contamination.

\section{Analytical procedures}

All the samples were filtered through the $0.02 \mu 1$ syringe filters. A $20 \mu \mathrm{l}$ injection of sample was used for manual injection into the HPLC Shimadzu equipped with the SPD-20 A UV-visible detector, the LC-20AT pump and the DGU-20A5 degasser. The C-18 column was used for the analysis purposes.

\section{HPLC optimization for the 1-OHPyr analysis}

The HPLC conditions were optimized for the 1-OHPyr. The optimization was carried out by running a series of standard dilutions for a number of times, and the conditions were observed for 3 consecutive days to validate optimization. The optimum conditions for the 1-OHPyr were as follows: $20 \mu$ injection, 250 bars pressure, a flow rate of $0.8 \mathrm{ml} / \mathrm{minute}$, with a run time of $10 \mathrm{~min}$, which was later reduced to $8 \mathrm{~min}$. The mobile phase consisted of acetonitrile and the HPLC gradient grade water of 70:30. The column temperature was set at $30^{\circ} \mathrm{C}$. Wavelength was set at $250 \mathrm{~nm}$, and the average elution time was $6.371 \mathrm{~min}$ (Table 1).

\section{RESULTS AND DISCUSSION}

The analysis of the 1-OHPyr was carried using the UVvisible detector. In published literature studies, the florescence detector is preferably used for the quantification of the urinary hydoxylated-PAHs biomarkers because of its high sensitivity, however, this is undermi- 
ning the importance of the UV-visible detections for this purpose since the UV-visible detector also gives good results, although it is not as sensitive as the florescent detector. In order to develop a new method based on the UV-visible detector system, we used 1-OHPyr concentrations up to the $\mathrm{nm} / \mathrm{l}$ level, with an average elusion time less than 10 min i.e., 6.37 min (Table 1 and 2). We have demonstrated that quantification of the 1-OHPyr using the UV-visible detector can also provide good results. The detector response provided a recovery percentage rate of more than $95 \%$ (Table 1 and 2). Overall recovery remained up to $108 \%$. The linearity of the method ranged between $\mathrm{R}^{2}=0.979$ and 0.989 . The overall percentage of the standard recovery is mentioned in the Table 1 and 2.

\section{A brief review of the 1-OHPyr quantification using UV-visible detectors}

A study by Ifegwu et al. [6], was reported from Nigeria, in which they used the UV-visible detector for quantification of the urinary 1-OHPyr (the reverse phase HPLC, $250 \mathrm{~nm}$ wavelength, X-Bridge C18 $(150 \times 4.6 \mathrm{~mm}, 5 \mu \mathrm{m}$ column). They used a flow rate of $1.2 \mathrm{ml} / \mathrm{min}$, and the mobile phase consisted of water and methanol at the ratio of $12: 88 \mathrm{v} / \mathrm{v}$
Table 1. Details of instrumental and analytical parameters used in the method development

\begin{tabular}{ll}
\hline \multicolumn{1}{c}{ Used in method } & \multicolumn{1}{c}{ Parameter } \\
\hline Instrumental conditions & \\
column & $\mathrm{C} 18-5 \mu \mathrm{m}, 25 \times 0.46 \mu \mathrm{m}$ \\
detector & $\mathrm{SPD}-20 \mathrm{~A}, \mathrm{UV}$-visible \\
elute A & acetonitrile 70\% \\
elute B & high purity HPLC grade water 30\% \\
mode & gradient \\
flow rate & $0.8 \mathrm{ml} / \mathrm{min}$ \\
column temperature & $30^{\circ} \mathrm{C}$ \\
wavelength & $\mathrm{UV}$ at 250 nm \\
injection volume & $20 \mu \mathrm{l}$ \\
run time & $8 \mathrm{~min}$ \\
mean RT & 6.3786 \\
Method performance & \\
LOD & $10 \mathrm{nmol} / \mathrm{l}$ \\
linearity & $0.9799-0.989$ \\
precision of retention & $2 \%, 6-7 \mathrm{runs}$ \\
time & \\
peak area precision & $2 \%, 6-7 \mathrm{runs}$ \\
\hline
\end{tabular}

RT - retention time; LOD - limit of detection; HPLC - high pressure liquid chromatography.

Table 2. Summary of standard dilutions, detector's response and percentage recovery

\begin{tabular}{|c|c|c|c|c|c|}
\hline \multirow{2}{*}{ No. } & \multirow{2}{*}{$\begin{array}{l}\text { Concentration spiked } \\
\qquad(\mu \mathrm{mol} / \mathrm{l})\end{array}$} & \multirow{2}{*}{$\begin{array}{l}\text { Response } \\
\text { (n) }\end{array}$} & \multicolumn{2}{|c|}{ Concentration calculated } & \multirow{2}{*}{$\begin{array}{l}\text { Recovery } \\
(\%)\end{array}$} \\
\hline & & & $\mu \mathrm{mol} / 1$ & $\mathrm{nmol} / \mathrm{l}$ & \\
\hline 1 & 1.000 & 3511 & 0.99 & 988.69 & 98.87 \\
\hline 2 & 0.500 & 2331 & 0.48 & 476.13 & 95.23 \\
\hline 3 & 0.250 & 2043 & 0.35 & 351.03 & 140.41 \\
\hline 4 & 0.125 & 1562 & 0.14 & 142.10 & 113.68 \\
\hline 5 & 0.050 & 1159 & 0.03 & 32.95 & 96.01 \\
\hline $\mathrm{M} \pm \mathrm{SD}$ & - & - & - & - & $108.84 \pm 17.14$ \\
\hline Intercept & - & - & - & - & 1234.90 \\
\hline Slope & - & - & - & - & 2302.20 \\
\hline
\end{tabular}

M - mean; SD - standard deviation. 
since no further details on performance and sensitivity of this method were reported in details.

In another method used by Anyakora et al. [7] (Nigeria), the quantification 1-OHPyr was carried out using reverse phase HPLC equipped with the UV-visible detector (242 nm wavelength) and the RP-Zorbax SB C-18 column $(75 \times 4.6 \mathrm{~mm}, 5 \mu \mathrm{m})$. The mobile phase consisted of a solution of 50:50 acetonitrile and water in isocratic mode with a flow rate of $1 \mathrm{ml} / \mathrm{min}$ whereas the column temperature was adjusted to $26^{\circ} \mathrm{C}$.

The detected concentration ranged between $0.1-1.3 \mu \mathrm{g} / \mathrm{ml}$. The calibration curve provided was in $\mu \mathrm{g} / \mathrm{ml}$ i.e., lower sensitivity than the currently developed methodology. In both of these methodologies, the elution time was exceptionally lower i.e., less than $3 \mathrm{~min}$, as compared to the current methodology. Another study was reported from China [8], in which the method to quantify the 1-OHPyr, and $\alpha-/ \beta$, naphthols simultaneously was developed.

The instrumental conditions were as follows: the HPLC equipped with a Diamonsil TMC 18 column (5 $\mu \mathrm{m}, 150 \times 4.6 \mathrm{~nm}$ ), a wavelength of $280 \mathrm{~nm}$, column temperature $35^{\circ} \mathrm{C}$, mobile phases $=$ methanol and ammonium acetate buffer solution (70:30) with a flow rate of $0.7 \mathrm{ml} / \mathrm{min}$. A comparison of the above discussed methodology shows that the method used by Yong-sheng et al. [8] seems to be the best method based on the UV detection, with an advantage of having analyzed 3 biomarkers of the PAHs exposure simultaneously. However, no further details on the performance of the method were available in any of these publications. The current methodology also shows a good level of sensitivity and specificity, therefore it is best for quantification of the 1-OHPyr in human urine in biomarker studies.

\section{CONCLUSIONS}

The current study provides a suitable protocol for quantification of the 1-OHPyr as a biomarker of exposure to the PAHs in human urine. Due to the rare usage of the UV-visible detection for quantification of the 1-OHPyr, this study has focused on developing a method which could possibly provide good results with the UV-visible detector. Moreover, the current method (provided the quantification of up to $\mathrm{nm} / \mathrm{l}$ ) seems more sensitive than the previously described UV-visible detector based methodologies, however the retention time is longer than it was indicated in the previous literature on this subject.

\section{ACKNOWLEDGMENTS}

The authors gratefully acknowledge the financial support of the Higher Education Commission of Pakistan, via granting indigenous scholarship for Ph.D. studies.

\section{REFERENCES}

1. Savitz DA, Stein CR, Bartell SM, Elston B, Gong J, Shin HM, et al. Perfluorooctanoic acid exposure and pregnancy outcome in a highly exposed community. Epidemiology. 2012;23(3):386-92, http://dx.doi.org/10.1097/EDE. 0b013e31824cb93b.

2. Shin HM, Vieira VM, Ryan PB, Steenland K, Bartell SM. Retrospective exposure estimation and predicted versus observed serum perfluorooctanoic acid concentrations for participants in the C8 Health Project. Environ Health Perspect. 2011;119(12):1760-5, http://dx.doi.org/10.1289/ehp. 1103729.

3. Hansen AM, Mathiesen L, Pedersen M, Knudsen LE. Urinary1-hydroxypyrene (1-HP) in environmental and occupational studies - A review. Int J Hyg Environ Health. 2008;211(5-6):471-503, http://dx.doi.org/10.1016/ j.ijheh.2007.09.012.

4. Sánchez-Guerra M, Pelallo-Martínez N, Díaz-Barriga F, Rothenberg SJ, Hernández-Cadena L, Faugeron S, et al. Environmental polycyclic aromatic hydrocarbon (PAH) exposure and DNA damage in Mexican children. Mutat Res. 2012;742(1-2):66-71, http://dx.doi.org/10.1016/j.mrgentox.2011.12.006. 
5. Jongeneelen FJ. Benchmark guideline for urinary 1-hydroxypyrene as biomarker of occupational exposure to polycyclic aromatic hydrocarbons. Ann Occup Hyg. 2001;45(1):3-13, http://dx.doi.org/10.1093/annhyg/45.1.3, http://dx.doi.org/10.1016/S0003-4878(00)00009-0.

6. Ifegwu C, Osunjaye K, Fashogbon F, Oke K, Adeniyi A, Anyakora C. Urinary 1-hydroxypyrene as a biomarker to carcinogenic polycyclic aromatic hydrocarbon exposure. Biomark Cancer. 2012;4:7-17.

7. Anyakora C, Chukelu A, Bolarinwa T, Afolami I, Coker $\mathrm{H}$, Ojobor P. Determination of 1-hydroxypyrene in urine samples of occupationally exposed subjects by HPLC method. Res Rev Biosci. 2008;2(2-6):1-4.

8. Wang Y, Wang Y, Cao X, Deng X, Wang X, Duan R. Simultaneous determination of 1-naphthnal,2-naphthnal and 1-hydroxypyrene in urine by high liquid chromatographyultraviolet photometric dection. Chinese J Health Lab Technol. 2009 [cited 2014 Apr 3];3:565-6. Available from: http:// www.oriprobe.com/journals/zgwsjyzz/2009_3.html.

This work is available in Open Access model and licensed under a Creative Commons Attribution-NonCommercial 3.0 Poland License - http://creativecommons.org/ licenses/by-nc/3.0/pl/deed.en. 